\title{
Family doctors call for guaranteed access to EMR data for research and quality improvement
}

- Cite as: CMAJ 2018 January 15;190:E60-1. doi: 10.1503/cmaj.109-5543

Posted on cmajnews.com on Dec. 20, 2017.

$\mathrm{T}$ o support quality improvement and research, family physicians and medical research networks need guaranteed, safe and affordable access to the data in electronic medical records (EMR) from the companies that provide the software, according to the College of Family Physicians of Canada.

The college, along with the Canadian Primary Care Sentinel Surveillance Network and the University of Toronto Practice-Based Research Network, recently issued a position statement decrying demands imposed by EMR vendors, such as prohibitive fees, restrictions on third-party extraction and analyses, and limitations on the type and frequency of data extractions.

About $85 \%$ of family physicians in Canada use EMRs. These can be used not only to manage the health care of patients, but also to help improve health outcomes and support medical research. Clinicians can sign up with research networks that extract deidentified patient data used to create quality-improvement reports for physicians - showing them how they compare with their peers on treating diabetes, for example - and conduct primary care research.

"Data in EMRs are an important source of information on strengths and areas of improvement at the practice level," said Dr. Jose Pereira, director of research for the College of Family Physicians of Canada.

But last spring, some EMR vendors suddenly cut off access to their data for third-party networks, said Pereira. The research networks were told they could

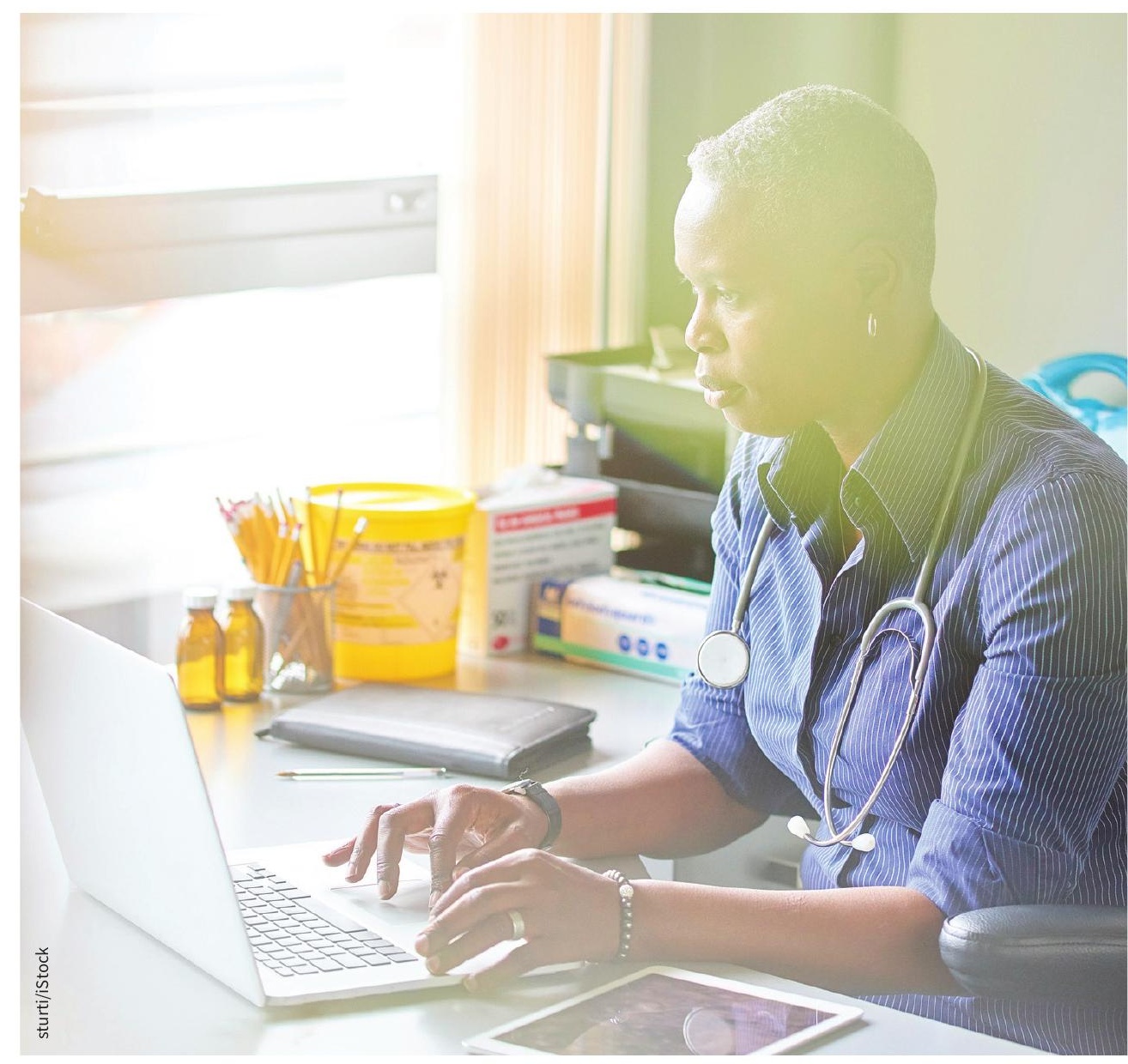

Who owns the data in an EMR? Patients? Doctors? EMR vendors?

receive monthly data extractions for an additional fee, but could not choose what those extractions contained. Anything beyond that regular package would cost extra. The cost for research networks to access the data was prohibitive, said Pereira - it could potentially have run into the hundreds of thousands of dollars depending on the extraction requested.

Eventually the vendors backed off, said Pereira. "But there is nothing to prevent them from doing it again in the future," he added. So the college put together the position statement to bring greater public attention to the issue. 
The fundamental question raised by the statement: Who owns the data in an EMR? Pereira said the general consensus among medical ethicists is that the data belong to patients, and clinicians are the custodians to ensure privacy. But by their actions last spring, it appears some vendors think differently. "By placing these restrictions, we believe that it is tantamount to saying that 'this is our data and you have to pay us to access it'," said Pereira. "Which we believe is wrong."

Some vendors, however, have expressed support for the college's statement.

"Vendors shouldn't restrict access to data," said Mike Checkley, president of QHR Technologies which offers the AccuroEMR medical records system. QHR participates in both the Canadian Pri- mary Care Sentinel Surveillance Network and the University of Toronto PracticeBased Research Network at no charge, he said. "It's just something we believe in."

Bill Gordon, CEO of AIHS, a nonprofit that offers the MOIS EMR system, said his company's goals of improving health care, the patient experience and per-capita costs means they are on board with the college's statement. "We support their initiatives and goals," he said.

Keeping the barriers low to accessing data also makes business sense for vendors. Half of QHR's new customers are switching from other EMR systems, said Checkley, and his company often has to deal with high fees and delays to switch the data over. "Fees are bad from a business perspective," he said; vendors should only be charging reasonable ser- vice fees to cover the cost of the actual work needed to prepare data, not for access to the data itself.

The college agrees with that position. "It will cost something, but it shouldn't be exorbitant," said Pereira. The college hopes the position paper starts a discussion about reasonable access to EMR data, and that politicians take notice and step in. In the United States, a similar situation resulted in federal legislation to guarantee access to EMR data for research purposes. "It needs to be raised to that level," said Pereira. "It may take federal or provincial legislation to ensure there is access to that data so that it is not monopolized or held hostage by a single vendor."

Brian Owens, St. Stephen, NB 